\title{
Relato de caso: fresamento solear para tratamento de ferida perfurocortante de sola em equinos
}

Nathalia Rodrigues Cavanha", Gabriela Silva Campos, Vanessa Luiza Marinheiro Silva, Veridiana Azevedo Nadruz, Luis Renato

Oseliero, Laura Pereira Pinseta

Jockey Club de São Paulo (JCSP), São Paulo, SP, Brasil

*Autor correspondente

e-mail: nath_cavanha@hotmail.com

\section{Resumo}

Um equino, macho, PSI, de 9 anos, estabulado no Jockey Club de São Paulo (JCSP), foi encontrado na cocheira apresentando sudorese e claudicação grau 5/5 (escala Stashak) do membro posterior direito (MPD). O cavalariço relatou a presença de objeto perfurante na sola, em região do ápice da ranilha do membro acometido. 0 animal foi encaminhado para o Hospital Veterinário do JCSP, porém o objeto, uma agulha de $13 \mathrm{~cm}$ utilizada para costurar sacos de serragem, já havia sido removida pelo cavalariço. No exame clínico, o animal apresentou frequência cardíaca $48 \mathrm{bpm}$, frequência respiratória $20 \mathrm{mpm}$, motilidade em todos os quadrantes, mucosas róseas, tempo de preenchimento capilar de 2 segundos e temperatura de $37,8^{\circ} \mathrm{C}$. 0 objetivo desse trabalho é relatar os métodos de diagnóstico e tratamento escolhidos para este caso. Após a limpeza do casco e exame detalhado, não foi encontrado o local da perfuração e o teste de pinçamento foi negativo. Foram administradas $2 \mathrm{~g}$ de fenilbutazona intravenosa, aplicado iodopolividona tópico na sola e feita botinha com EVA (espuma vinílica acetinada) no MPD. No dia seguinte à internação, a ferradura foi retirada, e durante o casqueamento, observou-se o início de extravasamento de líquido sinovial na região apontada como área de penetração do objeto. Foram realizadas três projeções radiográficas (dorsoplantar, lateromedial e skyline), sendo que na segunda projeção foi utilizado um guia metálico para avaliar a profundidade, extensão e trajetória do objeto. 0 exame radiográfico demonstrou acometimento de estruturas importantes como a região de inserção do tendão flexor digital profundo (TFDP) e a bursa do navicular. Optou-se pela realização do "Fresamento solear" (Técnica do "Streetnail”), com auxílio de um trépano para exposição da região afetada, e realização da limpeza (solução de iodopovidona - 3 ml diluídos em 1 litro de ringer lactato) e drenagem do local. Foi aplicado antibiótico em pó (Pentabiótico ${ }^{\circledR}$ ) diretamente na ferida cirúrgica e feita bandagem para proteger o casco de umidade e sujidades. As medicações póscirúrgicas utilizadas foram gentamicina (7 dias, 6,6mg/kg, IV, SID), penicilina (7 dias, 20000 UI, IM, BID), 
tramadol (5 dias, $2 \mathrm{mg} / \mathrm{kg}$, IM, SID), cetoprofeno ( 5 dias, $2,2 \mathrm{mg} / \mathrm{kg}$, IV, SID), omeprazol (30 dias, $4 \mathrm{mg} / \mathrm{kg}$, VO, SID) e dipirona ( 5 dias, $25 \mathrm{mg} / \mathrm{kg}$, IV, SID). No dia seguinte à penetração da agulha, foi realizada perfusão regional na veia digital plantar com $1.250 \mathrm{mg}$ de amicacina, $5 \mathrm{ml}$ de cloridrato de lidocaína $2 \%$ e $10 \mathrm{ml}$ de solução salina $0,9 \%$, sendo este procedimento repetido a cada dois dias em um total de sete aplicações, além do pedilúvio com permanganato de potássio por 20 minutos, curativo e bandagem com material absorvente e EVA. 0 grau de claudicação reduziu e a perfusão regional passou para uma vez por semana. Entretanto, após seis dias, o animal apresentou piora e a perfusão regional não pôde ser feita (vasos estavam muito danificados). Na artrocentese, o líquido sinovial apresentou-se turvo e de coloração sanguinolenta. Decidiuse fazer a lavagem da articulação interfalangeana distal, utilizando-se um litro de solução de ringer com lactato e aplicação de $500 \mathrm{mg}$ de amicacina. No total, foram quatro lavagens com intervalo de três dias e, após esse período, o animal já apresentava melhoras significativas do líquido sinovial e da claudicação (2/5). Após o término das lavagens, o animal permaneceu no hospital por 10 dias e em seguida foi casqueado e ferrado com uma ferradura talonada $(1,5 \mathrm{~cm}) .0$ animal teve alta 20 dias depois, sem apresentar claudicação evidente ao passo e foi indicado o uso da ferradura especial até futuras avaliações. Segundo Auer and Stick (2012), o prognóstico é reservado, e se diagnosticado e tratado precocemente, a chance de sucesso aumenta. Devido à rápida intervenção e tratamento imediato, o resultado obtido foi a melhora da claudicação e, consequentemente, um prognóstico melhor do que o descrito em literatura.

Palavras-chave: Streetnail. Bursa do navicular. Perfurocortante. 